\title{
Preparation and Stabilization of Ag Nanoparticles in 1-Amino-4-methylpiperazine
}

\author{
Heon-Soo Park, ${ }^{\dagger, \downarrow}$ Ueon Sang Shin, ${ }^{\dagger, *}$ Hae-Won Kim, ${ }^{\dagger, \&, \&}$ and Myoung-Seon Gong ${ }^{\dagger, \ldots, *}$ \\ 'Department of Nanobiomedical Science \& WCU Research Center, Dankook University Graduate School, Korea \\ "E-mail:msgong@dankook.ac.kr \\ *Institute of Tissue Regeneration Engineering (ITREN), Dankook University, Korea \\ ${ }^{\S}$ Department of Biomaterials Science, School of Dentistry, Dankook University, Korea \\ Received October 9, 2010, Accepted November 17, 2010
}

\begin{abstract}
Uniform $\mathrm{Ag}$ nanoparticles $(<10 \mathrm{~nm})$ were effectively prepared in 1-amino-4-methylpiperazine as a solvent with multiple functions including reduction and stabilization. An Ag-complex such as $\mathrm{Ag}_{2}(\mathrm{ehac})_{2}(\mathrm{eha})_{2}(\mathrm{ehac}=2$-ethylhexylammonium carbamate; eha =2-ethylhexylamine) was used as an Ag-precursor, whereas the usage of a salt such as $\mathrm{AgNO}_{3}$ showed the formation of $\mathrm{Ag}$ nanoparticles in larger and irregular size $(30-500 \mathrm{~nm})$. The $\mathrm{Ag}$ nanoparticles $(<10 \mathrm{~nm})$ prepared by using the Ag-complex could also be effectively stabilized by 1-amino-4-methylpiperazine. Transmission electron micrographs confirmed that the Ag particles were spherical and in the nanometer size.
\end{abstract}

Key Words: Ag Nanoparticles, 1-Amino-4-methylpiperazine, Multifunctional solvent

\section{Introduction}

The synthesis of metal nanoparticles with sizes ranging from $1-10 \mathrm{~nm}$ has recently been the focus of many studies due to their potential applications. ${ }^{1,2}$ Silver nanoparticles (Ag-NPs) have received considerable attention in a variety of areas because of their unique antimicrobial properties, ${ }^{3-5}$ especially in medicalrelated fields due to their potential for use in wound dressings, contraceptive devices, surgical instruments and bone prostheses. ${ }^{6,7}$ To enable the production of nanoparticles on a large scale under simple and mild conditions, chemical approaches using series of reductants and stabilizers have been extensively developed. $^{8-16}$ The reducing and stabilizing abilities of the compounds used in such reactions may play an important role in the growth control of the metal nanoparticles. For example, a weak reductant and an electron-rich stabilizer may be favorable for control of the size and morphology of the metal nanoparticles obtained. $^{13-16}$

Here, we report a new preparation method of Ag-NPs $(<10$ $\mathrm{nm}$ ) using 1-amino-4-methylpiperazine as a weak reducing agent and a solvating and stabilizing agent of nanoparticles. An Agcomplex such as $\mathrm{Ag}_{2}(\mathrm{ehac})_{2}(\mathrm{eha})_{2}(\mathrm{ehac}=2$-ethylhexylammonium carbamate; eha $=2$-ethylhexylamine $)^{17-26}$ was used as an Ag-precursor. During stirring for $3-12 \mathrm{~h}$ at $50{ }^{\circ} \mathrm{C}$, uniform Ag-NPs with sizes of $<10 \mathrm{~nm}$ were synthesized.

\section{Experimental}

Reagents and Analyses. 1-Amino-4-methylpiperazine (AMP) and $\mathrm{AgNO}_{3}$ were obtained from commercial sources (SigmaAldrich or Merck) and used without further purification. An isopropyl alcohol solution of Ag-complex with 2-ethylhexyl amine and 2-ethylhexylammonium carbamate $(\mathrm{Ag}=10 \mathrm{wt} \%)$ was purchased from InkTec Co., Ltd., Korea. Size and morphology of the as-prepared Ag-NPs were observed using a Philips TECNAI-FE12 transmission electron microscope (TEM, $120 \mathrm{kV})$. Briefly, the particles were dispersed in methanol, after which a drop of the solution was placed on a carbon-coated copper grid and allowed to air-dry. The X-ray diffraction (XRD) patterns were recorded using a RIGAKU ROTAFLEX RAD-B diffractometer (Rigaku Corp., Japan) with $\mathrm{Cu}$ target $\mathrm{Cu} \mathrm{K} 1$ radiation, a tube voltage of $40 \mathrm{KV}$ and $60 \mathrm{~mA}$ in the range of 5 $60^{\circ}$. Organic compounds were characterized by fast-atom bombardment mass spectroscopy (FAB-MS) (JMS-700, Jeol, Japan) and gas chromatography/mass selective detector (GC/MSD) (Varian 4000 instrument).

Synthesis of Silver Nanoparticles. $3.5 \mathrm{~mL}$ of Ag-complex or $\mathrm{AgNO}_{3}$ solution in AMP in a range of $0.025-0.01 \mathrm{M}$ was prepared and then stirred at $50{ }^{\circ} \mathrm{C}$. After a few hours, the solution color changed yellowish and then brown, indicating the formation of Ag-NPs. The progress of the reaction was monitored periodically by UV-vis spectroscopy at 3, 6, 9, 12 and $24 \mathrm{~h}$. Ag-NPs which were collected by centrifugation were characterized by TEM and XRD techniques.

\section{Results and Discussion}

The reducing ability of a reductant plays an important role in the size and morphology control of the metal nanoparticles obtained. AMP, which was utilized as a solvent, is a weak reducing agent as well as a good stabilizing agent. Two types of $\mathrm{Ag}$ compounds were employed as precursors, $\mathrm{AgNO}_{3}$ as an inorganic salt and $\mathrm{Ag}_{2}(\mathrm{ehac})_{2}(\mathrm{eha})_{2}(\mathrm{ehac}=2$-ethylhexylammonium carbamate; eha $=2$-ethylhexylamine) as an organometallic complex.

To monitor the growth of nanoparticles in AMP, the progress of the reaction was recorded periodically by UV-vis spectroscopy. In the presence of the Ag-complex in AMP solution and upon stirring, a rapid color change was observed from colorless to yellow or brown. As shown in the UV-vis spectra of Fig. 1, when the reaction time was extended to 6, 9, 12 and $24 \mathrm{~h}$, the specific absorption which occurred at $403 \mathrm{~nm}$ in $3 \mathrm{~h}$ was slightly shifted to $422 \mathrm{~nm}$ and the intensity decreased to the level before the reaction. These findings indicate that the formation, 


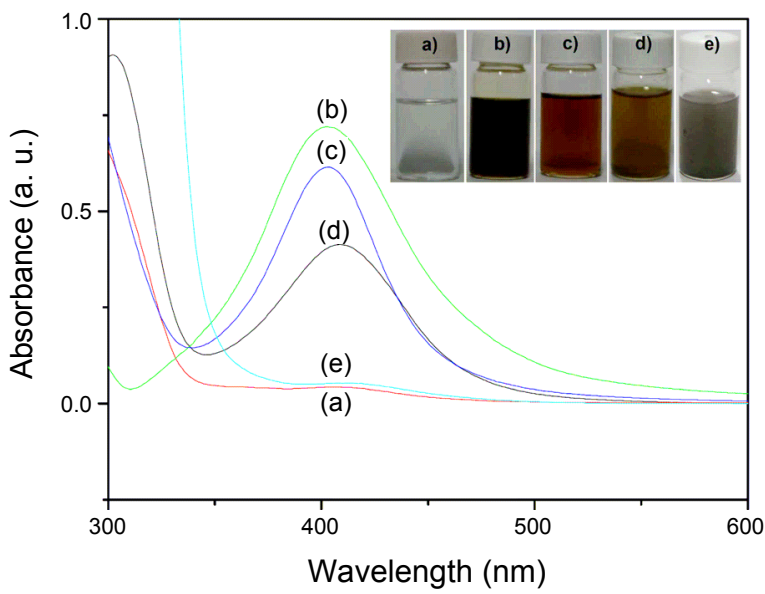

Figure 1. UV-vis spectra and photos of AMP solutions with Ag-NPs after reaction for (a) 0, (b) 3, (c) 6, (d) 12 and e) $24 \mathrm{~h}$.

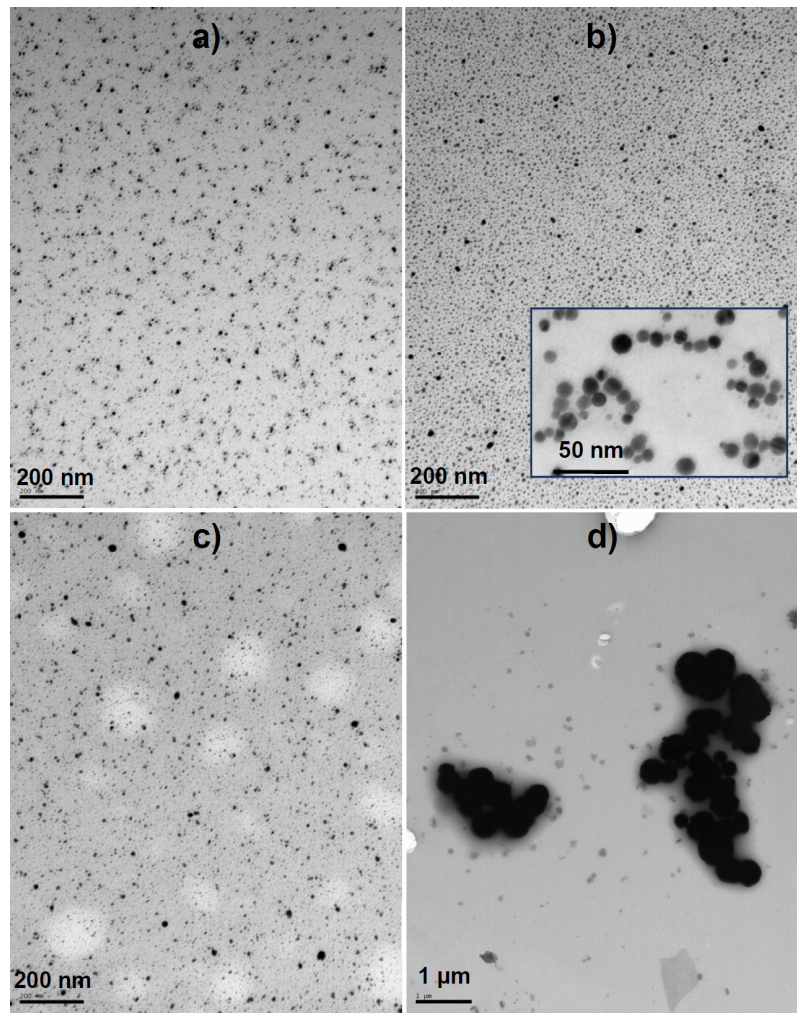

Figure 2. Transmission electron microscopic images of Ag-NPs prepared from Ag complex for (a) 3, (b) 6 and (c) $12 \mathrm{~h}$ and (d) from $\mathrm{AgNO}_{3}$ after $12 \mathrm{~h}$ of reaction: Inset in (b) shows a magnified image of Ag-NPs formed after $6 \mathrm{~h}$.

growth and precipitation of nanoparticles occurred, which could be confirmed in the photos in the inset of Fig. 1. However, upon changing the Ag-precursor to $\mathrm{AgNO}_{3}$, more rapid growth and precipitation of nanoparticles was observed, which was confirmed through a rapid color change. This difference may have occurred because naked $\mathrm{Ag}(\mathrm{I})$ ions of $\mathrm{AgNO}_{3}$ are surrounded directly by AMP molecules, which enables them to be easily reduced, whereas $\mathrm{Ag}(\mathrm{I})$ ions of $\mathrm{Ag}$ complexes are strongly coordinated with ligands such as 2-ethylhexylammonium carba- (a)

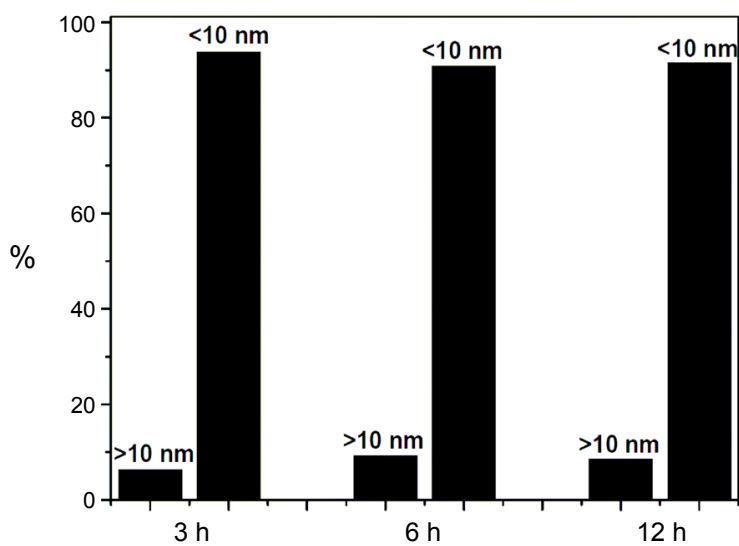

(b)

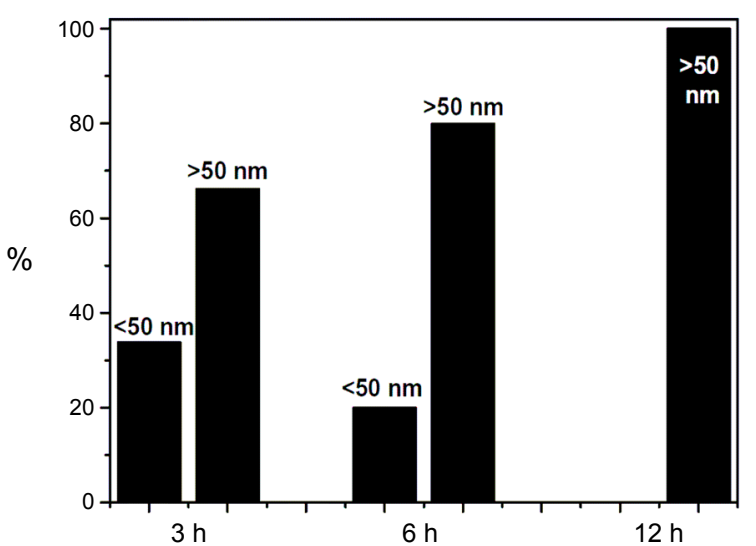

(c)

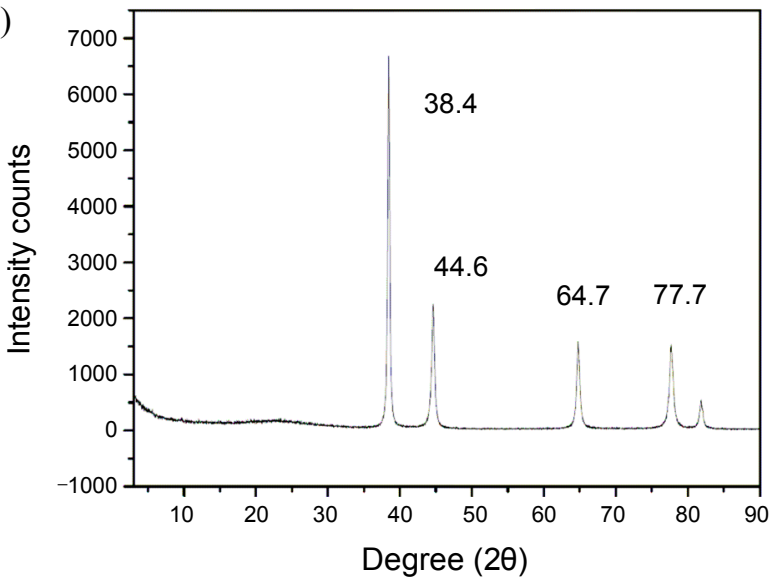

Figure 3. Size distribution (determined by calculation based on several TEM images) of $\mathrm{Ag}(0)$-NPs prepared from (a) $\mathrm{Ag}_{2}$ (ehac) $)_{2}(\mathrm{eha})_{2}$ and (b) $\mathrm{AgNO}_{3}$ and (c) powder X-ray diffraction pattern of $\mathrm{Ag}(0)$-NPs prepared from $\mathrm{Ag}_{2}(\mathrm{ehac})_{2}(\mathrm{eha})_{2}$.

mate and 2-ethylhexylamine, even in AMP solution. When the reaction temperature increased to $50{ }^{\circ} \mathrm{C}, 2$-ethylhexylammonium carbamate ligands on $\mathrm{Ag}(\mathrm{I})$ ions could be slowly decomposed to 2-ethylhexylamine and carbon dioxide, causing the $\mathrm{Ag}(\mathrm{I})$ ions to be exposed to AMP molecules.

TEM studies of Ag-NPs were conducted to evaluate the shape and size of the particles formed in the presence of $\mathrm{Ag}_{2}(\mathrm{ehac})_{2}$ (eha) $)_{2}$ and $\mathrm{AgNO}_{3}$ after 3, 6, and $12 \mathrm{~h}$. As shown in Fig. 2, spherical nanoparticles with a size less than $10 \mathrm{~nm}$ were generally 
(a)

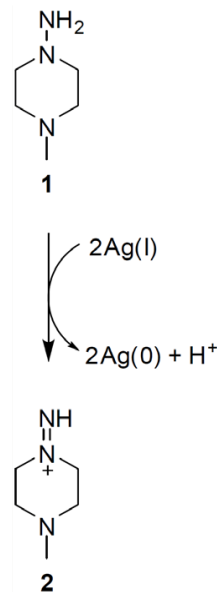

(b)
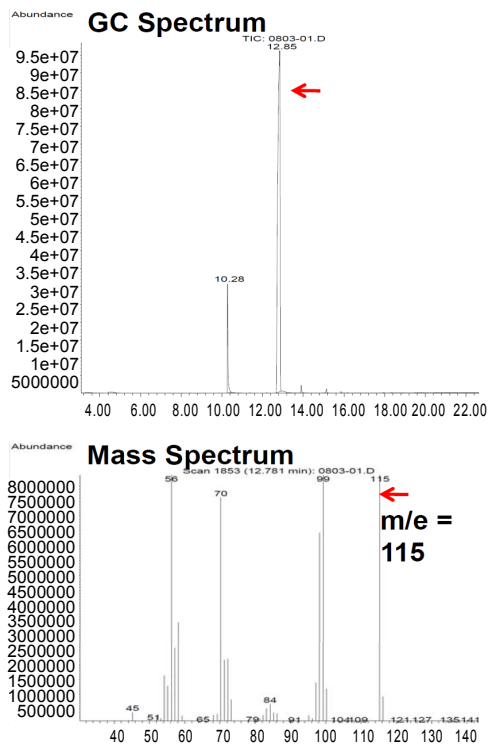

(c)

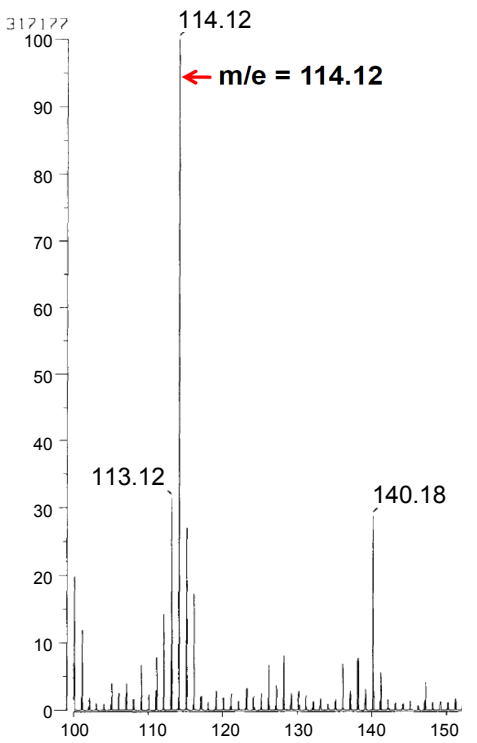

Figure 4. (a) Proposed mechanism for a role of 1-amino-4-methylpiperazine (1) in reducing Ag(I) ions, (b) GC-MS spectra of 1-amino-4methylpiperazine 1 before the reaction and (c) FAB mass spectrum of the iminium ion 2 formed within the reaction mixture after $6 \mathrm{~h}$ of the reaction.

formed between 3 - $12 \mathrm{~h}$ for the case of Ag-complex, whereas the formation of particles up to $500 \mathrm{~nm}$ was observed in the presence of $\mathrm{AgNO}_{3}$. These results speak that the stability of the as-prepared Ag-NPs in the reaction condition can be strongly influenced by the molecule structure of Ag-precursor. When compared to various amine stabilizers (their single alkyl chains have 12 - 18 carbon atoms) employed in the previous studies, ${ }^{15,16}$ AMP used in our experiment has very short alkyl chain. Nevertheless the uniform particles were formed after $6 \mathrm{~h}$. However, the average size of the particles $(<10 \mathrm{~nm})$ was relatively a little big than those $(<5 \mathrm{~nm})$ prepared in the presence of amines with the longer alkyl chain length.

The particle size distributions were calculated based on the TEM studies for reaction times of 3, 6 and $12 \mathrm{~h}$ (Fig. 3a and b). To collect Ag-NPs and evaluate their powder X-ray diffraction pattern, the brown-colored reaction mixture produced from Agcomplex solution after $6 \mathrm{~h}$ of reaction was centrifuged and the upper phase was removed. The lower phase was diluted with new AMP and centrifuged again. This washing process was repeated several times. After allowing the concentrated solution to stand for several days, Ag-NPs were deposited on a glass, which was subjected to a powder X-ray diffractometer. The powder X-ray diffraction pattern of the nanoparticles showed peaks at $38.4,44.6,64.7$, and $77.7^{\circ}$, confirming the presence of $\operatorname{Ag}(0)$ in the sample (Fig. $3 \mathrm{c}$ ). Specifically, the peak at $38.8^{\circ}$ with prominent peak counts confirmed the presence of $\operatorname{Ag}(0)$, which is the same as in the JCPDS cards.

Based on the observation and characterization of as-prepared Ag-NPs, we should assume that AMP molecules 1 play a role as a hydride donor. As proposed in Fig. 4, a hydride ion that might be detached from the primary amine to form an iminium ion 2, reduces $\operatorname{Ag}(\mathrm{I})$ ion to $\operatorname{Ag}(0)$ specious. According to our assumption, we confirmed the formation of the iminium ion 2 by GC-MS and FAB mass spectroscopic methods (Fig. 4). The
FAB mass spectra of the reaction mixture after $6 \mathrm{~h}$ of stirring at $50{ }^{\circ} \mathrm{C}$ showed a prominent peak at $m / z=114$, which corresponded to $2, \mathrm{C}_{5} \mathrm{H}_{12} \mathrm{~N}_{3}{ }^{+}$, whereas the peaks related to AMP (1), $\mathrm{C}_{5} \mathrm{H}_{13} \mathrm{~N}_{3}$, at $m / z=115$, were prominently observed in the GCMS mass spectra.

\section{Conclusion}

We report here a new method for the preparation of Ag-NPs $(<10 \mathrm{~nm})$ using AMP as not only a weak reducing agent, but also a solvating and stabilizing agent of nanoparticles. During stirring a silver complex such as $\mathrm{Ag}_{2}(\mathrm{ehac})_{2}(\mathrm{eha})_{2}(\mathrm{ehac}=2-$ ethylhexylammonium carbamate; eha $=2$-ethylhexylamine) in AMP at $50{ }^{\circ} \mathrm{C}$ for $3-12 \mathrm{~h}$, uniform $\mathrm{Ag}$ nanoparticles with sizes of 2 to $10 \mathrm{~nm}$ were effectively synthesized, whereas from a silver salt such as $\mathrm{AgNO}_{3}$ silver particles with sizes of about 30 - $500 \mathrm{~nm}$ were obtained. The prepared Ag nanoparticles $(<10$ $\mathrm{nm}$ ) could be effectively stabilized within the reaction solution of AMP as well. This method will be potential for use as a tool for preparation of metallic nanoparticles to enable control of the particle size in the nanometer scale as well as the uniformity of the particle size.

Acknowledgments. This work was supported by the Priority Research Centers Program (grant\#: 2009-0093829) and the WCU (World Class University) program (grant\#: R31-10069) through the National Research Foundation (NRF) funded by the Ministry of Education, Science and Technology of Korea.

\section{References}

1. Lewis, L. N. Chem. Rev. 1993, 93, 2693.

2. Dupont, J.; Fonseca, G. S.; Umpierre, A. P.; Fichtner, P. F. P.; Teixeira, S. R. J. Am. Chem. Soc. 2002, 124, 4228.

3. Singh, M.; Sinha, K.; Mandal, R. K. Mater. Lett. 2009, 63, 425.

4. Yon, J. N.; Jamie, R. L. Sci. Total Enviro. 2008, 400, 396. 
5. Jeon, H. J.; Yi, S. C.; Oh, S. G. Biomaterials 2003, 24, 4921.

6. Cohen, M. S.; Stern, J. M.; Vanni, A. J.; Kelley, R. S.; Baumgart, E.; Field, D.; Libertino, J. A.; Summerhayes, I. C. Surg. Infect. (Larchmt) 2007, 8, 397.

7. Fu, J.; Ji, J.; Fan, D.; Shen, J.; Biomed. J. Mater. Res. A 2006, 79, 665 .

8. Ahmadi, T. S.; Wang, Z. L.; Green, T. C.; Henglein, A.; El-Sayed, M. A. Science 1996, 272, 1924.

9. Brust, M.; Walker, M.; Bethell, D.; Schiffrin, D. J.; Whyman, R. J. Chem. Soc., Chem. Commun. 1994, 801.

10. Burshtain, D.; Zeiri, L.; Efrima, S. Langmuir 1999, 15, 3050.

11. Han, M. Y.; Quek, C. H.; Huang, W.; Chew, C. H.; Gan, C. M. Chem. Mater. 1999, 11, 1144.

12. Wang, J. G.; Neoh, K. G.; Kang, E. T. J. Colloid Interface. Sci. 2001, 239, 78 .

13. Khanna, P. K.; Gokhale, R.; Subbarao, V. V. V. S.; Vishwanath, A. K.; Das, B. K.; Satyanarayana, C. V. Mater. Chem. Phy. 2005, 92, 229.

14. Li, Y.; El-Sayed, M. A. J. Phys. Chem. B 2001, 105, 8938.

15. Yamamoto, M.; Kashiwagi, Y.; Nakamoto, M. Langmuir 2006,
22,8581 .

16. Kashiwagi, Y.; Yamamoto, M.; Nakamoto, M. J. Colloid Interface Sci. 2006, 300, 169.

17. Park, M. S.; Lim, T. H.; Jeon, Y. M.; Kim, J. G.; Joo, S. W.; Gong, M. S. Macromol. Res. 2008, 16, 308.

18. Park, M. S.; Lim, T. H.; Jeon, Y. M.; Kim, J. G.; Joo, S. W.; Gong, M. S. Sens. Actuators B 2008, 133, 166

19. Park, M. S.; Lim, T. H.; Jeon, Y. M.; Kim, J. G.; Joo, S. W.; Gong, M. S. J. Colloid Interface Sci. 2008, 321, 60.

20. Lim, T. H.; Jeon, Y. M.; Gong, M. S. Polymer(Korea) 2009, 33, 33.

21. Jeon, Y. M.; Cho, H. N.; Gong, M. S. Macromol. Res. 2009, 17, 2.

22. Hong, H. K.; Gong, M. S.; Park, C. K. Bull. Korean Chem. Soc. 2009, 30, 2669.

23. Hong, H. K.; Park, C. K.; Gong, M. S. Bull. Korean Chem. Soc. 2010, 31, 1252.

24. Park, H. S.; Park, H. S.; Gong, M. S. Polymer (Korea) 2010, 34 , 144.

25. Park, H. S.; Park, H. S.; Gong, M. S. Bull. Korean Chem. Soc. 2010, 31, 2575.

26. Park, H. S.; Park, H. S.; Gong, M. S. Macromol. Res. 2010, 18, 897. 